\title{
Articles
}

\section{The impact of a family history of Type II (non-insulin-dependent) diabetes mellitus on the risk of diabetic nephropathy in patients with Type I (insulin-dependent) diabetes mellitus}

\author{
J.A. Fagerudd, K. J. Pettersson-Fernholm, C. Grönhagen-Riska, P.-H. Groop \\ Department of Medicine, Division of Nephrology, Helsinki University Central Hospital, Finland
}

\section{Abstract}

Aims/hypothesis. There is substantial evidence for a role of genetic factors in the development of diabetic nephropathy. In Pima Indians, a link between susceptibility to diabetic nephropathy and Type II (non-insulin-dependent) diabetes mellitus has been proposed. In this study, our aim was to examine the association between a family history of Type II diabetes and diabetic nephropathy in patients with Type I (insulin-dependent) diabetes mellitus.

Methods. In a cross-sectional case-control study, we assessed the prevalence of Type II diabetes in the parents of 137 Type I diabetic patients with diabetic nephropathy (albuminuria $>300 \mu \mathrm{g} / \mathrm{min}$ in two of three overnight urine collections) compared with the parents of 54 Type I diabetic patients without nephropathy (albuminuria $<20 \mu \mathrm{g} / \mathrm{min}$ ).

Results. Thirty-four $(25 \%)$ of the patients with nephropathy compared with five $(9 \%)$ of the patients without nephropathy had a parental history of Type II diabetes $(p=0.019)$. A parental history of Type II diabetes was associated with a three-fold risk [odds ratio 2.95 (95\% confidence interval: 1.03 to 8.40 ), $p=0.043$ ] of diabetic nephropathy after adjustment for sex, glycaemic control and family history of hypertension. Furthermore, there was an excess of risk factors for development of Type II diabetes (higher fasting plasma glucose concentrations, higher prevalence of hypertension, higher waist-hip ratio and a tendency towards more glucose intolerance) among previously non-diabetic parents of patients with nephropathy.

Conclusion/interpretation. Genetic or environmental factors or both related to familial Type II diabetes increase susceptibility to diabetic nephropathy in patients with Type I diabetes. [Diabetologia (1999) 42: 519-526]

Keywords Diabetic nephropathy, Type I (insulin-dependent) diabetes mellitus, familial Type II (non-insulin-dependent) diabetes mellitus, genetic factors, risk factor.
Diabetic nephropathy is a condition characterized by persistent albuminuria, an increase in arterial blood pressure, a relentless decline in renal function and in-

Received: 30 September 1998 and in final revised form: 28 December 1998

Corresponding author: Dr. P.-H. Groop, M.D., DMSc, Department of Medicine, Division of Nephrology, Helsinki University Central Hospital, P. O. Box 346, FIN-00029 HUCH, Finland Abbreviations: WHR, waist-hip ratio; U-AER, urinary albumin excretion rate; ESRD, end stage renal disease; NA, not assessed. creased cardiovascular morbidity and mortality. It occurs in $10-40 \%$ of patients with Type I (insulin-dependent) diabetes mellitus [1-3]. Although a strict glycaemic control diminishes the risk of diabetic microvascular complications [4], the development of diabetic nephropathy cannot be explained by poor glycaemic control alone [5]. Diabetic nephropathy has been found to cluster in families [6-8] to an extent that cannot be explained by shared environmental factors alone [9]. In addition, the majority of family studies have reported an excess of hypertension $[10-13]$ and cardiovascular disease $[14,15]$ in parents of Type I diabetic patients with nephropathy. There- 
fore, substantial evidence suggests a role for genetic factors in the development of diabetic nephropathy.

Type II (non-insulin-dependent) diabetes is considered to be a heterogenous disease resulting from defects in both insulin secretion and insulin action [16]. Although the exact pathogenetic mechanisms are poorly understood, the disease seems to be influenced by genetic factors since the concordance rate in identical twins is high [17], as is the life-time risk of Type II diabetes in the offspring of Type II diabetic patients [18]. Type I diabetes, on the other hand, has been thought to be a more homogenous disease characterized by acute insulin deficiency due to autoimmune destruction of pancreatic beta cells. It could be hypothesized, however, that a certain degree of heterogeneity exists also in Type I diabetes. In this respect, Type I diabetic patients with a family history of Type II diabetes could represent a distinct subphenotype, especially since Type II diabetes is more prevalent among relatives of Type I diabetic patients compared with relatives of non-diabetic subjects [19]. So far, little is known about the impact of a family history of Type II diabetes in patients with Type I diabetes.

In non-diabetic subjects with a family history of Type II diabetes, a spectrum of metabolic disturbances, such as insulin resistance, abdominal obesity, increased blood pressure and lipid abnormalities, has been described [20,21]. Similar metabolic and haemodynamic disturbances have also been found in the early stages of diabetic nephropathy in Type I diabetes [22-26]. Furthermore, in Pima Indians, a link between familial Type II diabetes and diabetic nephropathy has been reported, since diabetic nephropathy in parents, compared with parental diabetes alone, is associated with an increased risk of diabetes in the offspring [27]. We hypothesized that a link between familial Type II diabetes and nephropathy exists also in Type I diabetes and, therefore, our aim was to examine the association between a family history of Type II diabetes and diabetic nephropathy in patients with Type I diabetes.

\section{Subjects and methods}

Subjects. After approval from the local ethics committee, 158 Type I diabetic patients with diabetic nephropathy were invited to participate in the study. The patients constituted a random sample of all Type I diabetic patients with diabetic nephropathy attending the renal outpatient clinic or the dialysis unit of Helsinki University Central Hospital between November 1995 and December 1997. Twenty-one patients were unwilling or unable to participate and, consequently, 137 Type I diabetic patients with diabetic nephropathy were included in the study. Thirty-four Type I diabetic patients with normal albumin excretion rate attending the diabetic outpatient clinic of the same hospital from September 1990 to February 1992 [24] were recruited consecutively. The control group was fur- ther increased by an advertisement in the newspaper of the Helsinki Diabetes Association. All Type I diabetic patients $(n=20)$ that responded to the advertisement and who fulfilled the inclusion criteria were included. Informed consent was obtained from all participating patients.

The clinical characteristics of the Type I diabetic patients are listed in Table 1. All patients had an onset of diabetes before the age of 30 years, had insulin treatment initiated within a year after diagnosis and had been uninterruptedly treated with insulin alone since then. At the time of the study all of them received multiple daily injections of insulin. All patients with diabetic nephropathy had present or past documentation of persistent macroalbuminuria [urinary albumin excretion rate (U-AER) exceeding $200 \mu \mathrm{g} / \mathrm{min}$ in at least two of three consecutive timed overnight urine collections] in the absence of any clinical or laboratory evidence of other kidney or renal tract disease. At the time of the study, $43 \%$ of the patients with diabetic nephropathy had progressed to end stage renal disease (ESRD). All patients in the control group had a duration of diabetes exceeding 15 years and a U-AER less than $20 \mu \mathrm{g} / \mathrm{min}$ in three overnight urine samples. None of the patients in the control group had a history of micro- or macroalbuminuria. The participating patients were interviewed using a standardized questionnaire regarding parents being alive or dead, age of the parents at the time of the study and parental diabetes or antihypertensive treatment. If a parent was dead, cause of death and age at death were asked for.

Assessment of family history of diabetes, hypertension and cardiovascular death. Information on vital status, diabetes, antihypertensive treatment and cardiovascular death was available in 377 (99\%), 377 (99\%), 369 (97\%) and 374 (98\%), respectively, of the the participating patients' parents. To confirm the cases of parental diabetes and to test the reliability of patientreported data on parental hypertension and cardiovascular death, information was obtained by interviewing living parents and by reviewing medical records and death certificates of dead parents. Confirmation of data was carried out in all parents classified as diabetic by their Type I diabetic offspring ( $n=66 ; 50$ of the patients with and 16 of the patients without nephropathy) and, furthermore, in a sample of 221 of all 311 (217 parents of patients with and 94 parents of patients without nephropathy) presumed non-diabetic parents. The sample of 221 presumed non-diabetic parents (138 of patients with and 83 of patients without nephropathy) was selected as follows: firstly, a medical history was obtained from the living parents in relation to the OGTT after data was collected from the patients ( $n=95$ and 55; see Assessment of glucose tolerance in previously non-diabetic parents). Secondly, to test the reliability of data on the presumed non-diabetic parents that did not attend the outpatient clinic, the validation procedure was further carried out in a subgroup of 71 parents $(n=43$ and 28) of whom 18 were alive $(n=14$ and 4$)$ and 53 were dead $(n=29$ and 24). A diagnosis of diabetes could not be confirmed in 16 parents while evidence of diabetes was found in none of the parents classified as non-diabetic by their Type I diabetic offspring. Thus, the diabetic patients identified parental diabetes with a specificity of $93 \%$ and a sensitivity of $100 \%$. The reliability of patient-reported data was similar in patients with and without nephropathy (specificity $93 \%$, sensitivity $100 \%$ in both groups) and was not substantially affected by parents being alive or dead (living parents: specificity $95 \%$, sensitivity $100 \%$, dead parents; specificity $88 \%$, sensitivity $100 \%$ ). Only confirmed cases of parental diabetes were included in the analysis. Diabetes was classified as Type I diabetes, if age at onset was less than or equal to 40 years and the parent had received treatment with insulin alone since diagnosis. All other cases 
Table 1. Clinical characteristics of the Type I diabetic patients with $(\mathrm{DN}+)$ and without nephropathy $(\mathrm{DN}-)$

\begin{tabular}{|c|c|c|c|}
\hline & $\mathrm{DN}+$ & $\mathrm{DN}-$ & $p$ \\
\hline$n$ & 137 & 54 & \\
\hline Male/female & $87 / 50$ & $25 / 29$ & $<0.05$ \\
\hline Age (years) & $42 \pm 1$ & $42 \pm 1$ & NS \\
\hline Onset of diabetes (years) & $12 \pm 1$ & $14 \pm 1$ & NS \\
\hline Diabetes duration (years) & $30 \pm 1$ & $28 \pm 1$ & NS \\
\hline \multicolumn{4}{|l|}{ BMI $\left(\mathrm{kg} / \mathrm{m}^{2}\right)$} \\
\hline \multicolumn{4}{|l|}{ WHR } \\
\hline male & $0.93 \pm 0.01$ & $0.87 \pm 0.01$ & $<0.01$ \\
\hline female & $0.85 \pm 0.01$ & $0.80 \pm 0.01$ & $<0.001$ \\
\hline \multicolumn{4}{|l|}{ Units of insulin/body weight (IU/kg) } \\
\hline male & $0.72 \pm 0.04$ & $0.65 \pm 0.03$ & NS \\
\hline female & $0.75 \pm 0.04$ & $0.59 \pm 0.03$ & 0.007 \\
\hline Diastolic blood pressure (mm Hg) & $86 \pm 1$ & $79 \pm 1$ & $<0.001$ \\
\hline Prevalence of hypertension $(\%)^{\mathrm{a}}$ & 96 & 13 & $<0.001$ \\
\hline $\mathrm{HbA}_{1 \mathrm{c}}(\%)$ & $8.9 \pm 0.1$ & $8.1 \pm 0.1$ & $<0.001$ \\
\hline Serum creatinine $(\mu \mathrm{mol} / \mathrm{l})$ & $173(68-1176)$ & $83(57-111)$ & $<0.001$ \\
\hline U-AER (not measured in ESRD $\mu \mathrm{g} / \mathrm{min}$ ) & $512(19-8936)$ & $4(1-19)$ & NA \\
\hline Proportion with ESRD $(+/-)$ & $59 / 78$ & - & NA \\
\hline \multicolumn{4}{|l|}{ Present ESRD treatment: } \\
\hline Kidney transplant & 37 & - & NA \\
\hline Haemodialysis & 11 & - & NA \\
\hline CAPD & 11 & - & NA \\
\hline
\end{tabular}

Data presented as means \pm SEM, median (range) or $\% .{ }^{a}$ Hypertension defined as antihypertensive treatment or arterial blood pressure $\geq 160 / 95 \mathrm{~mm} \mathrm{Hg}$ or both

of confirmed parental diabetes were classified as Type II diabetes.

The sensitivity of proband-reported parental hypertension was found to be $89 \%$, while the specificity was $90 \%$. Parental cardiovascular death was considered present, if the proband reported death from cardiac causes, stroke or rupture of an aortic aneurysm. In the subgroup of $76(51 \%)$ of the 149 dead parents for whom death certificates were obtained, data given by the patients identified cardiovascular disease as immediate or underlying cause of death in their parents with a sensitivity and specificity of $83 \%$ and $97 \%$, respectively.

Assessment of glucose tolerance in previously non-diabetic parents. At the time of the study, 138 parents of patients with nephropathy and 69 parents of patients without nephropathy were alive and had no history of diabetes. Those who lived within a reasonable distance from the research facilities in Helsinki and who were not suffering from any major disabling condition were invited to take part in an OGTT. The OGTT was therefore done in 95 (69\%) and 55 (76\%; $p=$ NS) living, nondiabetic parents of patients with and without nephropathy.

The parents who had an OGTT were studied in the morning after an overnight fast. All participating parents gave their informed consent. A careful medical history regarding diabetes, cardiovascular disease, hypertension, smoking habits and regular medication was taken from all participating parents using a standardized questionnaire. Plasma glucose was measured in duplicates in the fasting state and at 30,60 and $120 \mathrm{~min}$ after ingestion of $75 \mathrm{~g}$ glucose in $200 \mathrm{ml}$ of water. Dia- betes and impaired glucose tolerance (IGT) in the OGTT were defined according to the 1985 WHO criteria [28]. Abnormal glucose tolerance was defined as IGT and diabetes combined. Incremental area under the glucose curve was calculated by the trapezoidal rule.

Body weight (to the closest $0.1 \mathrm{~kg}$ ) and height (to the closest $\mathrm{cm}$ ) were measured in indoor clothing. BMI was calculated as weight $(\mathrm{kg}) /[\text { height }(\mathrm{m})]^{2}$. Waist circumference was measured midway between the iliac crest and the lowest rib and hip circumference at the widest part of the gluteal region. Waist-hip ratio (WHR) was calculated as waist $(\mathrm{cm}) / \mathrm{hip}(\mathrm{cm})$. Smoking was defined as present smoking of at least one daily cigarette, cigar or pipe during 1 year before the examination. Blood pressure was measured auscultatory with a calibrated mercury sphygmomanometer from the righthand arm with the subject in sitting position after a 5 min rest. Systolic (Korotkoff I) and diastolic (Korotkoff V) blood pressure was measured twice and the mean value was used in analyses.

Laboratory tests. Plasma glucose was measured with a glucose oxidase method using a Beckman Glucose Analyser II (Beckman, Fullerton, Calif., USA) with a within assay coefficient of variation of $1.0 \%$. Urinary albumin concentration was determined by radioimmunoassay (Albumin-RIA, Pharmacia, Uppsala, Sweden) with a within assay coefficient of variation of $4.1 \%$. Glycated haemoglobin was measured by high pressure liquid chromatography (normal range: 4.0-6.0\%) and serum creatinine by a kinetic Jaffe' method (normal range: women 50-110, men 55-115 $\mu \mathrm{mol} / \mathrm{l}$ ). 
Statistical analysis. The significance of difference in categorical variables between the groups was tested with the Chi-squared test. The significance of difference in continuous variables was tested using the Student's $t$ test (normally distributed) and with the Mann-Whitney $U$ test (non-normally distributed). Overall and cardiovascular parental death rate was calculated with a Kaplan-Meier analysis using a SPSS 7.5.1 statistical package (SPSS, Chicago, USA), which takes into account the variability in length of follow-up. In the analysis, parents contributed person-years to follow-up until death or, whether alive, until the age at the time of the study. When overall death rate was assessed, life or death status was used as the censoring indicator, while death from cardiovascular disease was used as censoring indicator in the cardiovascular death rate analysis. The significance of the difference in survival between the two groups was determined using the logrank test. To evaluate the independent association between familial factors and diabetic nephropathy, a multiple forward stepwise logistic regression analysis was done including potential confounding factors and the adjusted odds ratios and the $95 \%$ confidence interval calculated (SPSS 7.5.1). A two-tailed $p$-value less than 0.05 was considered statistically significant.

\section{Results}

Parental overall and cardiovascular mortality. Of the 271 parents of patients with nephropathy and 106 parents of patients without nephropathy where data on life or death status was available, $107(39 \%)$ and 34 (32\%) were dead (difference: $7 \%$ (95\% CI: -3 to $18 \%, p=$ NS). A Kaplan-Meier survival analysis showed a higher overall death rate among parents of patients with nephropathy compared with parents of patients without (log rank test: $p=0.039$ ). An additional survival analysis was done dealing exclusively with parental death from cardiovascular cause. No significant difference was found in the cardiovascular death rate between the parents in the two groups although there was a tendency towards higher cardiovascular death rate among mothers of patients with nephropathy compared with mothers of patients without nephropathy $(p=0.095)$ in a sex-stratified analysis.

Parental history of diabetes and hypertension. Sixtysix parents (54 of patients with and 12 of patients without nephropathy, $p=0.048$ ) were reported to have diabetes by their Type I diabetic offspring. A diagnosis of diabetes could not be confirmed in 16 parents (ten of patients with, six of patients without nephropathy). As shown in Table 2, confirmed diabetes was more prevalent among parents of patients with nephropathy. After classification of confirmed cases of diabetes into Type I and Type II diabetes, there was an excess of Type II diabetes among parents of patients with nephropathy. The median age at onset of Type II diabetes was 60 years (range: 40-89) in parents of patients with nephropathy and 66 years $(56-85)$ in parents of patients without nephropathy $(p=\mathrm{NS})$. In addition, there was an excess of hypertension in parents of patients with nephropathy.
Table 2. Parental diabetes and hypertension according to presence $(\mathrm{DN}+)$ or absence $(\mathrm{DN}-)$ of diabetic nephropathy in the Type I diabetic offspring

\begin{tabular}{lccl}
\hline & DN + & DN - & $p$ \\
\hline Diabetes & $44(16 \%)$ & $6(6 \%)$ & $<0.01$ \\
Type I diabetes & $6(2 \%)$ & $0(0 \%)$ & NS \\
Type II diabetes & $38(14 \%)$ & $6(6 \%)$ & $<0.05$ \\
Hypertension & $94(36 \%)$ & $20(19 \%)$ & $<0.01$ \\
\hline
\end{tabular}

Data is number (\%)

Table 3. Adjusted odds ratios for variables independently associated with diabetic nephropathy

\begin{tabular}{lll}
\hline Variable & OR $(95 \% \mathrm{CI})$ & $p$ \\
\hline $\mathrm{HbA}_{1 \mathrm{c}}$ & $1.76(1.29-2.40)$ & $<0.01$ \\
Parental Type II diabetes & $2.95(1.03-8.40)$ & $<0.05$ \\
Male sex & $2.30(1.13-4.67)$ & $<0.05$ \\
Parental hypertension & $2.06(1.00-4.24)$ & $<0.05$ \\
\hline
\end{tabular}

Variables included in the forward stepwise multiple logistic regression analysis: parental history of Type II diabetes, parental history of hypertension, sex, diabetes duration, smoking and $\mathrm{HbA}_{1 \mathrm{c}}$

In a patient-based analysis, $34(25 \%)$ of the patients with nephropathy compared with five $(9 \%)$ of patients without nephropathy had a confirmed diagnosis of Type II diabetes in one or both parents [difference $16 \%$ (95\% CI: 5 to $26 \%), p=0.019$ ]. Corresponding proportions of patients with and without nephropathy with antihypertensive treatment in one or both parents were $56 \% \quad(n=75)$ and $36 \%$ $(n=19)$; difference $20 \% \quad(95 \%$ CI: 4 to $35 \%)$, $p=0.015$. Parental history of Type II diabetes and hypertension, sex, diabetes duration, smoking and $\mathrm{HbA}_{1 \mathrm{c}}$ were entered into a forward stepwise multiple logistic regression analysis (Table 3 ). In addition to glycaemic control and male sex, both parental history of Type II diabetes and hypertension were found to be independently associated with diabetic nephropathy with odds ratios of 2.9 and 2.1, respectively. To quantify the effect of parental hypertension on the odds ratio for parental Type II diabetes, parental hypertension was omitted from the model. In this model, the sex- and $\mathrm{HbA}_{1 \mathrm{c}}$-adjusted odds ratio for parental Type II diabetes was 3.3 (95\% CI: 1.2 to 9.2).

Patients with a family history of Type II diabetes were slightly older ( $44 \pm 1$ vs $41 \pm 1$ years, $p=0.039$ ), had higher WHR (men: $0.95 \pm 0.01$ vs $0.91 \pm 0.01$, $p=0.039$; women $0.85 \pm 0.02$ vs $0.82 \pm 0.01, p=$ $0.054)$, higher systolic blood pressure $(154 \pm 3$ vs $146 \pm 2, p=0.040)$, a higher prevalence of nephropathy ( 87 vs $68 \%, p=0.019)$ and a family history of hypertension ( 67 vs $46 \%, p=0.019$ ) compared with patients without a family history of Type II diabetes.

Characteristics of parents without a history of diabetes. Data on the 95 parents of patients with nephropa- 
Table 4. Characteristics of parents without a history of diabetes

\begin{tabular}{|c|c|c|c|}
\hline & $\mathrm{DN}+$ & $\mathrm{DN}-$ & $p$ \\
\hline$n$ & 95 & 55 & \\
\hline Fathers/mothers & $36 / 59$ & $22 / 33$ & NS \\
\hline Age (years) & $65 \pm 1$ & $65 \pm 1$ & NS \\
\hline \multicolumn{4}{|l|}{ BMI $\left(\mathrm{kg} / \mathrm{m}^{2}\right)$} \\
\hline fathers & $28.0 \pm 0.7$ & $26.1 \pm 0.9$ & NS \\
\hline mothers & $28.4 \pm 0.6$ & $27.9 \pm 0.7$ & NS \\
\hline \multicolumn{4}{|l|}{ WHR } \\
\hline fathers & $0.97 \pm 0.01$ & $0.94 \pm 0.01$ & $<0.05$ \\
\hline mothers & $0.85 \pm 0.01$ & $0.83 \pm 0.01$ & NS \\
\hline \multicolumn{4}{|l|}{ Fasting plasma } \\
\hline glucose (mmol/1) & $5.7 \pm 0.1$ & $5.4 \pm 0.1$ & $<0.05$ \\
\hline $\begin{array}{l}\text { Area under glucose } \\
\text { curve }(\mathrm{mmol} / 1 \times \mathrm{min})\end{array}$ & $326 \pm 18$ & $300 \pm 21$ & NS \\
\hline \multicolumn{4}{|l|}{$\begin{array}{l}\text { Abnormal glucose } \\
\text { tolerance }(\%)\end{array}$} \\
\hline all & 33 & 24 & NS \\
\hline fathers & 34 & 14 & $\begin{array}{l}\text { NS } \\
(0.085)\end{array}$ \\
\hline mothers & 33 & 30 & NS \\
\hline Smoking (\%) & 19 & 24 & NS \\
\hline $\begin{array}{l}\text { Antihypertensive } \\
\text { therapy (\%) }\end{array}$ & 34 & 18 & $<0.05$ \\
\hline
\end{tabular}

thy and 55 parents of patients without nephropathy without a history of diabetes who had an OGTT are in Table 4. Parents of patients with nephropathy had higher fasting plasma glucose concentrations and were more often treated for hypertension. Fathers of patients with nephropathy had higher WHR and tended to be more glucose intolerant compared with fathers of patients without nephropathy.

\section{Discussion}

In our case-control study, we report evidence of an association between a familial history of Type II diabetes and diabetic nephropathy in patients with Type I diabetes. Type I diabetic patients with Type II diabetes in one or both parents had a three-fold risk of diabetic nephropathy compared with patients without parental Type II diabetes. This association was independent of familial hypertension and potential confounding factors.

Our observation is based on a higher prevalence of a family history of Type II diabetes in Type I diabetic patients with diabetic nephropathy compared with those without diabetic renal disease. Before any further conclusions can be drawn, any effect of potential confounding factors must be carefully evaluated. The prevalence of diabetes increases steeply with age [29] and a difference in prevalence could be the result of a difference in age between the groups of parents. In line with previous reports $[14,15]$, however, survival was poorer among parents of patients with nephropa- thy. The time at risk of developing diabetes was thus shorter among parents of patients with nephropathy, an observation that further strengthens our finding of an increased prevalence of Type II diabetes in this group. Furthermore, sex-specific effects of a family history of Type II diabetes [20] have been reported. There were more men among patients with nephropathy, probably due to the fact that male sex is a risk factor for nephropathy [1] and no attempt was made to match the patients with and without nephropathy for this variable. Logistic regression analysis showed, however, an association of familial history of Type II diabetes with diabetic nephropathy that was independent of sex.

In Pima Indians, diabetic nephropathy in parents, compared with parental diabetes alone, has been found to be associated with an increased risk for diabetes in the offspring [27]. Another study in the same population suggested an increased prevalence of proteinuria in Type II diabetic patients with maternal Type II diabetes compared with those without [30]. Therefore, in Type II diabetes, a link between familial Type II diabetes and development of diabetic renal complications seems likely. Familial factors have also been extensively studied in Type I diabetes. Studies evaluating parental hypertension $[10,31,32]$ and prevalence $[14,33]$ or mechanisms [34] of parental cardiovascular disease have reported no excess of parental diabetes in Type I diabetic patients with nephropathy. All these studies, however, were rather small and not specifically designed to study the impact of parental diabetes. A Swedish case-control study in young Type I diabetic patients [13] found only a small increase in parental Type II diabetes among patients with micro- or macroalbuminuria, but the results should be interpreted with caution due to the small number of parents with Type II diabetes.

Two recent large-scale case-control studies have reported data on the impact of a family history of diabetes on the development of micro- and macrovascular complications in Type I diabetes. The Pittsburgh Epidemiology of Diabetes Complications Study [35] found an association between a family history of Type II diabetes and coronary heart disease in Type I diabetic patients. In support of our findings, the prevalence of nephropathy was higher by univariate analysis among Type I diabetic patients with familial Type II diabetes compared with those without. An association of parental diabetes with albuminuria in the Type I diabetic offspring was also observed in the EURODIAB Study [36]. The association was strongest in women, with an odds ratio of albuminuria of 1.4 in female patients with a family history of diabetes. It was weaker in men and only borderline significant in the whole study population. In our study, parental Type II diabetes was associated with an almost three-fold risk of nephropathy which exceeds the 
$95 \%$ confidence interval of the EURODIAB Study. The classification of patients into albuminuric and normoalbuminuric in the EURODIAB Study, however, was based on a single urine collection. Furthermore, the control group had a relatively short duration of diabetes and could therefore have included a proportion of patients at considerable risk of subsequent development of nephropathy. Misclassification of cases and control subjects in a study with a casecontrol design will lead to an underestimation of any associated phenomenon. Therefore, the stronger association between diabetic nephropathy and parental Type II diabetes found by us is most likely a result of the more robust classification used in our study.

We have recently confirmed the previously somewhat controversial association of predisposition to hypertension and diabetic nephropathy in Type I diabetes [10-12, 31]. Our finding here of an adjusted odds ratio of 2.1 for nephropathy in patients reporting antihypertensive therapy in one or both parents provide additional evidence for this association. It should be noted that a family history of Type II diabetes was associated with nephropathy independently of a family history of hypertension. Therefore, a family history of Type II diabetes and familial predisposition to hypertension seem to influence the risk of nephropathy by way of different, but so far unexplained, mechanisms.

We can only speculate about the mechanisms linking a family history of Type II diabetes to diabetic nephropathy in Type I diabetes. Type II diabetes is a heterogenous disease that results from defects in both insulin action and production [16]. The definition of parental Type II diabetes used in our study was based on historical data, which makes a more precise subphenotyping impossible, and the parents with Type II diabetes will indeed include subjects with a different aetiology and with a different impact on the offspring with Type I diabetes. The characteristics of the selected group of surviving non-diabetic parents, however, showed an excess of abdominal obesity, higher fasting plasma glucose and more hypertension in parents of patients with diabetic nephropathy, all factors associated with the insulin resistance syndrome. Furthermore, the Type I diabetic patients with diabetic nephropathy had a higher WHR despite similar BMI compared with patients without nephropathy. Since abdominally distributed fat is closely linked to insulin resistance [37], this indirectly supports the previous observations, that increased albuminuria is associated with insulin resistance in both Type I [22, 23] and Type II diabetes [38]. Also, insulin resistance has been found to be predictive of subsequent development of microalbuminuria [39], which could indicate a causal relation between insulin resistance and development of diabetic microvascular complications. Insulin resistance could therefore be the common denominator linking a family history of Type II diabetes to the development of diabetic nephropathy in Type I diabetes. On the other hand, Type I diabetic patients with residual beta-cell function are less prone to develop microvascular complications compared with patients with complete loss of beta-cell function [40]. An inherited defect in insulin production, perhaps resulting in a more complete loss of beta-cell function at the time of onset of diabetes, could therefore also increase the risk of diabetic nephropathy in Type I diabetic patients with a family history of Type II diabetes.

What are the implications of our finding of an excess of Type II diabetes in parents of patients with nephropathy? A sedentary family lifestyle could possibly predispose both to parental Type II diabetes and nephropathy in the offspring - for instance, there are some indications of a protective effect of physical exercise on the development of retinopathy in Type I diabetes [41]. Although common environmental factors may be important in the genesis of both Type II diabetes in parents and diabetic nephropathy in the offspring with Type I diabetes, one must also consider genetic factors in the observed familial clustering of the two diseases. The Trp64Arg mutation of the $\beta_{3^{-}}$ adrenergic-receptor gene, previously associated with earlier onset of Type II diabetes in Pima Indians [42], abdominal obesity and insulin resistance [43] and an increased tendency to gain weight in Caucasians [44], has recently been associated with the development of both proliferative retinopathy [45] and diabetic nephropathy [46] in Japanese Type II diabetic patients. Therefore, based on our findings, the $\beta_{3}$ adrenergic-receptor gene as well as any other gene related to Type II diabetes, insulin resistance, impaired insulin secretion or obesity, need to be tested as candidate genes for diabetic nephropathy also in Type I diabetic patients.

In conclusion, a family history of Type II diabetes is associated with a three-fold risk of diabetic nephropathy in Type I diabetes. Genetic or environmental factors or both related to familial Type II diabetes seem to increase susceptibility to diabetic nephropathy in patients with Type I diabetes.

Acknowledgements. We acknowledge our laboratory technicians R. Laine and T. Riihimäki, our research assistant A. Kehusmaa and A.-M. Teppo, M.Sc., S. Stenman, M.D. and C. Forsblom, M.D. for their skillful assistance in carrying out this study. This study was supported by grants from The Finnish Medical Society, The Wilhelm and Else Stockmann Foundation and The Perklen Foundation.

\section{References}

1. Andersen A, Christiansen J, Andersen J, Kreiner S, Deckert T (1983) Diabetic nephropathy in Type I (insulin-dependent) diabetes: an epidemiological study. Diabetologia 25: 496-501 
2. Krolewski A, Warram J, Christlieb A, Busick E, Kahn C (1985) The changing natural history of nephropathy in Type I diabetes. Am J Med 78: 785-794

3. Bojestig M, Arnqvist H, Hermansson G, Karlberg B, Ludvigsson J (1994) Declining incidence of nephropathy in insulin-dependent diabetes mellitus. N Engl J Med 330: $15-18$

4. The Diabetes Control and Complications Trial Research Group (1993) The effect of intensive treatment of diabetes on the development and progression of long-term complications in insulin-dependent diabetes mellitus. $\mathrm{N}$ Engl $\mathbf{J}$ Med 329: 977-986

5. Deckert T, Poulsen J (1981) Diabetic nephropathy: fault or destiny? Diabetologia 21: 178-183

6. Seaquist E, Goetz F, Rich S, Barbosa J (1989) Familial clustering of diabetic kidney disease. Evidence for genetic susceptibility to diabetic nephropathy. N Engl J Med 320: 1161-1164

7. Borch-Johnsen K, Nørgaard K, Hommel E et al. (1992) Is diabetic nephropathy an inherited complication? Kidney Int 41: 719-722

8. Quinn M, Angelico M, Warram J, Krolewski A (1996) Familial factors determine the development of diabetic nephropathy in patients with IDDM. Diabetologia 39: 940-945

9. Khoury M, Beaty T, Liang K-Y (1988) Can familial aggregation of disease be explained by familial aggregation of environmental risk factors? Am J Epidemiol 127: 674-683

10. Viberti G, Keen H, Wiseman M (1987) Raised arterial pressure in parents of proteinuric insulin dependent diabetics. BM J 295: 515-517

11. Krolewski A, Canessa M, Warram J et al. (1988) Predisposition to hypertension and susceptibility to renal disease in insulin-dependent diabetes mellitus. N Engl J Med 318: 140-145

12. Fagerudd J, Tarnow L, Jacobsen P et al. (1998) Predisposition to essential hypertension and development of diabetic nephropathy in IDDM patients. Diabetes 47: 439-444

13. Rudberg S, Stattin E-L, Dahlquist G (1998) Familial and perinatal risk factors for micro- and macroalbuminuria in young IDDM patients. Diabetes 47: 1121-1126

14. Earle K, Walker J, Hill C, Viberti G (1992) Familial clustering of cardiovascular disease in patients with insulin-dependent diabetes and nephropathy. N Engl J Med 326: 673-677

15. Tarnow L, Fagerudd J, Rossing P, Nielsen F, Cambien F, Parving $H$ (1998) Cardiovascular morbidity and early mortality clusters in parents of IDDM patients with diabetic nephropathy. Diabetologia 41 [Suppl 1]:1125, A291 [Abstract]

16. DeFronzo R (1988) The triumvirate: $\beta$-cell, muscle, liver. A collusion responsible for NIDDM. Lilly lecture 1987. Diabetes 37: 667-687

17. Newman B, Selby J, King M-C, Slemenda C, Fabsitz R, Friedman G (1987) Concordance for Type II (non-insulindependent) diabetes mellitus in male twins. Diabetologia 30: 763-768

18. Köbberling J, Tillil H (1982) Empirical risk figures for first degree relatives of non-insulin dependent diabetics. In: Köbberling J, Tattersall R (eds) Serono Symposium No.47. The Genetics of Diabetes Mellitus. Academic Press, London, New York, pp 201-209

19. Dahlquist G, Blom L, Tuvemo T, Nyström L, Sandström A, Wall S (1989) The Swedish childhood diabetes study - results from a nine year case register and a one year case-referent study indicating that Type I (insulin-dependent) diabetes mellitus is associated with both Type II (non-insulindependent) diabetes mellitus and auto-immune disorders. Diabetologia 32: 2-6
20. Groop L, Forsblom C, Lehtovirta M et al. (1996) Metabolic consequences of a family history of NIDDM (The Botnia Study). Evidence for sex-specific parental effects. Diabetes 45: $1585-1593$

21. Haffner S, Stern M, Hazuda H, Mitchell B, Patterson J, Ferrannini E (1989) Parental history of diabetes is associated with increased cardiovascular risk factors. Arteriosclerosis 9: 928-933

22. Yip J, Mattock M, Morocutti A, Sethi M, Trevisan R, Viberti G (1993) Insulin resistance in insulin-dependent diabetic patients with microalbuminuria. Lancet 342: 883-887

23. Mäkimattila S, Virkamäki A, Groop PH et al. (1996) Chronic hyperglycemia impairs endothelial function and insulin sensitivity via different mechanisms in IDDM. Circulation 94: 1276-1282

24. Groop PH, Elliott T, Ekstrand A et al. (1996) Multiple lipoprotein abnormalities in type 1 diabetic patients with renal disease. Diabetes 45: 974-979

25. Stuhldreher W, Becker D, Drash A et al. (1994) The association of waist/hip ratio with diabetes complications in an adult IDDM population. J Clin Epidemiol 47: 447-456

26. Parving H, Smidt U, Frisberg B, Bonnevie-Nielsen V, Andersen A (1981) A prospective study of glomerular filtration rate and arterial blood pressure in insulin-dependent diabetics with diabetic nephropathy. Diabetologia 20: 457-461

27. McCance D, Hanson R, Pettitt D et al. (1995) Diabetic nephropathy: a risk factor for diabetes mellitus in offspring. Diabetologia 38: 221-226

28. World Health Organization Study Group on Diabetes Mellitus (1985), Technical Report Series No 727, WHO Geneva

29. Harris M, Hadden W, Knowler W, Bennett P (1987) Prevalence of diabetes and impaired glucose tolerance and plasma glucose levels in U.S. population aged 20-74 yr. Diabetes 36: 523-34

30. Nelson R, Pettitt D, de Courten M, Hanson R, Knowler W, Bennett P (1996) Parental hypertension and proteinuria in Pima Indians with NIDDM. Diabetologia 39: 433-438

31. Jensen J, Mathiesen E, Nørgaard K et al. (1990) Increased blood pressure and erythrocyte sodium/lithium countertransport activity are not inherited in diabetic nephropathy. Diabetologia 33: 619-624

32. Walker J, Tariq T, Viberti G (1990) Sodium-lithium countertransport activity in red cells of patients with insulin dependent diabetes and their parents. BMJ 301: 635-638

33. Nørgaard K, Mathiesen E, Hommel E, Jensen J, Parving H-H (1991) Lack of familial predisposition to cardiovascular disease in Type 1 (insulin-dependent) diabetic patients with nephropathy. Diabetologia 34: 370-372

34. De Cosmo S, Bacci S, Piras G et al. (1997) High prevalence of risk factors for cardiovascular disease in parents of IDDM patients with albuminuria. Diabetologia 40: 1191-1196

35. Erbey J, Kuller L, Becker D, Orchard T (1998) The association between a family history of type 2 diabetes and coronary artery disease in a type 1 diabetes population. Diabetes Care 21: 610-614

36. Roglic G, Colhoun H, Stevens L et al. (1998) Parental history of hypertension and parental history of diabetes and microvascular complications in insulin-dependent diabetes mellitus: the EURODIAB IDDM Complications Study. Diabet Med 15: 418-426

37. Banerji M, Chaiken R, Gordon D, Kral J, Lebovitz H (1995) Does intra-abdominal adipose tissue in black men determine whether NIDDM is insulin-resistant or insulinsensitive? Diabetes 44: 141-146 
38. Groop L, Ekstrand A, Forsblom C et al. (1993) Insulin resistance, hypertension and microalbuminuria in patients with type 2 (non-insulin-dependent) diabetes mellitus. Diabetologia 36: 642-647

39. Nosadini R, Solini A, Velussi M et al. (1994) Impaired insulin-induced glucose uptake by extrahepatic tissue is hallmark of NIDDM patients who have or will develop hypertension and microalbuminuria. Diabetes 43: 491-499

40. Sjöberg S, Gunnarsson R, Gjötterberg M, Lefvert A, Persson A, Östman J (1987) Residual insulin production, glycaemic control and prevalence of microvascular lesions and polyneuropathy in long-term Type I (insulin-dependent) diabetes mellitus. Diabetologia 30: 208-213

41. Cruickshanks K, Moss S, Klein R, Klein B (1992) Physical activity and proliferative retinopathy in people diagnosed with diabetes before age 30 yr. Diabetes Care 15: 1267-1272

42. Walston J, Silver K, Bogardus C et al. (1995) Time of onset of non-insulin-dependent diabetes mellitus and genetic variation in the $\beta_{3}$-adrenergic-receptor gene. $\mathrm{N}$ Engl $\mathrm{J}$ Med 333: 343-347

43. Widén E, Lehto M, Kanninen T, Walston J, Shuldiner A, Groop L (1995) Association of a polymorphism in the $\beta_{3}$ adrenergic-receptor gene with features of the insulin resistance syndrome in Finns. N Engl J Med 333: 348-351

44. Clément K, Vaisse C, Manning B et al. (1995) Genetic variation in the $\beta_{3}$-adrenergic-receptor and an increased capacity to gain weight in patients with morbid obesity. $\mathrm{N}$ Engl J Med 333: 352-354

45. Sakane N, Yoshida T, Yoshioka K et al. (1997) $\beta_{3}$-adrenoreceptor gene polymorphism: a newly identified risk factor for proliferative retinopathy in NIDDM patients. Diabetes 46: $1633-1636$

46. Sakane N, Yoshida T, Yoshioka K et al. (1998) Trp64Arg mutation of $\beta_{3}$-adrenoceptor gene is associated with diabetic nephropathy in Type II diabetes mellitus. Diabetologia 41: 1533-1534 [letter] 